\title{
IMPLEMENTASI INFOGRAFIS PADA VIDEO BASIC MACHINE OPERATION MSP PT. INFINEON TECHNOLOGIES BATAM
}

\author{
Getha Febriyani Putri*, Sandi Prasetyaningsih** \\ Department of Multimedia and Network Engineering, Batam Polytechnic \\ ** Department of Multimedia and Network Engineering, BatamPolytechnic
}

\begin{tabular}{|c|c|}
\hline Article Info & ABSTRAK \\
\hline Article history: & $\begin{array}{l}\text { Sebagai bentuk informasi terhadap proses pengoperasian mesin atau } \\
\text { fasilitas untuk menunjang suatu pekerjaan, PT. Infineon Technologies }\end{array}$ \\
\hline $\begin{array}{l}\text { Received Oct } 12^{\text {th }}, 2020 \\
\text { Revised Nov } 10^{\text {th }}, 2020 \\
\text { Accepted Des } 16^{\text {th }}, 2020\end{array}$ & $\begin{array}{l}\text { Batam memanfaatkan teknologi multimedia sebagai media } \\
\text { penyampaian informasi kepada karyawan agar lebih memahami } \\
\text { bagaimana proses pengerjaan dan cara mengoperasikan mesin yang } \\
\text { akan digunakan. Multimedia yang digunakan adalah media video yang }\end{array}$ \\
\hline $\begin{array}{l}\text { Keyword: } \\
\text { PT. Infineon Technologies } \\
\text { Batam } \\
\text { Video } \\
\text { Infografis } \\
\text { Action Research }\end{array}$ & $\begin{array}{l}\text { berisi tentang proses produksi dari industri tersebut. Salah satu video } \\
\text { yang akan dihasilkan, yaitu video basic machine operation MSP yang } \\
\text { ditargetkan untuk karyawan operator di area MSP (mark, scan, pack), } \\
\text { yaitu proses akhir dalam pembuatan produk semikonduktor. Produk } \\
\text { yang dihasilkan dalam tugas akhir ini adalah implementasi infografis } \\
\text { pada video tersebut, menggunakan metode penyelesaian action } \\
\text { research agar video yang disampaikan dapat dipahami dengan cepat } \\
\text { dan mudah oleh karyawan PT. Infineon Technologies Batam. Video ini } \\
\text { nantinya akan digunakan sebagai salah satu video training kepada } \\
\text { karyawan baru untuk mengetahui hal dasar saat bekerja di area } \\
\text { produksi, yaitu Alat Pelindung Diri (APD) yang digunakan, Kesehatan } \\
\text { dan Keselamatan Kerja (K3), dan flowchart penggabungan motherlot } \\
\text { dengan babylot pada proses MSP. }\end{array}$ \\
\hline
\end{tabular}

Copyright @ 2020 Institute of Advanced Engineering and Science. All rights reserved.

Corresponding Author:

First Author,

Departement of Multimedia and Network Engineering,

Batam Polytechnic,

Batam Centre, Jl.Ahmad Yani, Tlk, Tering, Kec. Batam Kota, Kota Batam, Kepulauan Riau.

Email: gfbryniptr89@gmail.com

Second Author,

Departement of Multimedia and Network Engineering,

Batam Polytechnic,

Batam Centre, Jl.Ahmad Yani, Tlk, Tering, Kec. Batam Kota, Kota Batam, Kepulauan Riau.

Email: sandi@polibatam.ac.id

\section{PENDAHULUAN}

Pada dunia industri yang bergerak di bidang manufacturing, suatu produk membutuhkan informasi agar meminimalisir kesalahan yang akan terjadi. Industri tersebut juga pasti memiliki fasilitas untuk menunjang pengerjaan. Sebagai contoh fasilitas yang dibutuhkan oleh industri adalah mesin. Saat mesin tersebut digunakan untuk pertama kalinya pasti diperlukan aturan dan cara dalam penggunaannya. PT. Infineon Technologies Batam memiliki 4 proses utama, yaitu assembly (front-end dan back-end), testing, dan MSP (mark, scan, pack). 
MSP (mark, scan, pack) merupakan proses akhir dalam proses produksi IC (integrated circuit) yang dihasilkan dan merupakan salah satu proses yang menarik untuk di jadikan sebagai salah satu video sebagai media training yang memiliki beberapa proses kesinambungan dengan teknologi saat ini, seperti saat material di scan menggunakan micro camera untuk menganalisa (scan) material agar tidak terjadinya kerusakan. Hasil akhir dari proses MSP ini adalah material yang sudah selesai melewati seluruh proses sebelumnya akan dimasukkan ke dalam reel seperti bentuk roll film dan di kemas dalam box seperti bentuk pizza box. Hal ini mendapat nilai tambah tersendiri dalam pendistribusian produk kepada konsumen.

PT. Infineon Technologies Batam juga merupakan salah satu industri semikonduktor yang menggunakan mesin sebagai salah satu fasilitas yang digunakan dalam proses produksi, sehingga membutuhkan sumber daya manusia untuk mengoperasikannya. Namun, sumber daya manusia tidak selamanya bekerja di tempat yang sama. Ada kalanya suatu perusahaan akan mengalami pergantian pekerja. Hal ini membutuhkan waktu untuk memberikan pelatihan kepada pekerja baru.

Karena terbatasnya informasi yang dimiliki, pekerja baru belum memahami tentang apa saja atribut yang akan digunakan, peringatan yang harus diketahui selama berada di area produksi, dan tahapan proses MSP. Maka, dibutuhkan pelatihan sebagai media informasi. Bentuk pelatihan yang diberikan dapat berupa pemberian materi atau sosialisasi. Namun, hal itu saja tidak cukup sebagai sumber informasi yang diberikan kepada pekerja baru. Oleh sebab itu, digunakan alternatif lain berupa video sebagai salah satu metode pemberi informasi mengenai dasar proses MSP dan lain sebagainya.

\section{LANDASAN TEORI}

\subsection{Motion Graphic}

Motion graphic yaitu grafis yang menggunakan video dan atau animasi untuk menciptakan ilusi dari gerak ataupun transformasi. Graphic design telah berubah dari static publishing dengan memanfaatkan teknologi komunikasi termasuk film, animasi, dan media interaktif [2].

Untuk membuat motion graphic yang efektif, maka diperlukan beberapa aspek, yaitu:

\section{Spatial}

Aspek yang terdiri dari ukuran, arah, arah acuan, arah gerakan. Gerakan akan dipengaruhi oleh gerakan lain dan pergerakan terhadap batas frame. Faktor tersebut penting sebagai pertimbangan ketika proses animasi bergerak selaras dan tidak saling tumpang tindih.

\section{Temporal}

Aspek ini terdiri dari time dan velocity yang memiliki peranan cukup besar dalam gerakan animasi. Di dunia video dan film, time menggambarkan secara numeric sebagai frame per second (fps). Frame rate menggambarkan kecepatan maksimum animasi untuk membuat ilusi yang berkelanjutan. Umumnya, frame rate pada motion picture adalah 29,97 fps.

\section{Live Action}

Aspek ini perlu diperhatikan ketika membuat live action termasuk bentuk atau konteks, seperti tone, contrast, lighting, depth of field, focus, camera angle, shot size, dan mobile framing.

\section{Typographic}

Aspek ini dilakukan untuk membangun sebuah pesan dalam desain grafis. Penggunaannya terdapat hal yang bisa dimanfaatkan sesuai dengan kebutuhan, misalnya tipe huruf, ukuran, dan lain-lain.

\subsection{Infografis}

Infografis merupakan desain grafis hasil dari penggabungan dari visualisasi data, ilustrasi, teks atau gambar menjadi sebuah bentuk untuk menyampaikan pesan tertentu. Infografis sama dengan public speaking dan dibagi menjadi tiga kategori, yaitu sebagai sarana informasi, hiburan, dan persuasi penonton sehingga dapat memberikan perhatian dan menyempatkan untuk membaca makna yang terkandung didalamnya. 


\subsection{Skala Likert}

Teknik pengukuran ini paling sering digunakan dalam riset penelitian. Pembuatan skala likert yaitu membuat beberapa pernyataan yang berhubungan dengan suatu isu atau objek, lalu subjek atau responden diminta untuk mengindikasikan tingkat kesetujuan atau ketidaksetujuan mereka terhadap masing-masing pernyataan. Pada umumnya, riset ini menggunakan lima angka penilaian, yaitu : (a) Sangat Setuju, (b) Setuju, (c) Tidak Berpendapat, (d) Tidak Setuju, (e) Sangat Tidak Setuju.

\subsection{Action Research}

Stringer (2014) menyatakan action research merupakan bentuk pendekatan sistematis yang memungkinkan orang menemukan solusi efektif terhadap masalah dalam kehidupan sehari-hari[6]. Salah satu metode tahapan yang digunakan pada tugas akhir ini adalah action research oleh Baskerville (1999) yang menggunakan lima fase sebagai siklus action research, yaitu diagnosing (diagnosa), action planning (perencanaan tindakan), action taking (pengambilan tindakan), evaluating (evaluasi), dan specifying learning (pembelajaran spesifik) seperti yang disajikan pada gambar 1 [1].

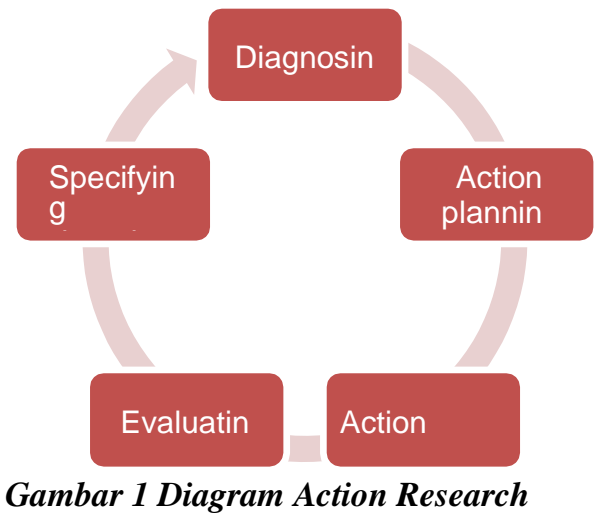

\section{Diagnosing}

Mendiagnosis sesuai dengan identifikasi masalah utama yang menjadi penyebab keinginan untuk berubah. Diagnosis melibatkan interpretasi diri terhadap masalah yang kompleks, bukan melalui reduksi dan penyederhanaan.

2. Action Planning

Dari hasil diagnosa tersebut kemudian menentukan tindakan yang akan dilakukan. Tindakan ini menunjukkan beberapa kondisi yang diinginkan untuk mencapai perubahan.

3. Action Taking

Implementasi tindakan yang direncanakan sebelumnya disesuaikan dengan konsep yang sudah dirancang sebelumnya.

4. Evaluating

Mengevaluasi hasil dari produk yang telah dibuat. Evaluasi mencakup menentukan apakah konsep tersebut dapat direalisasikan. Ketika konsep ini berhasil, maka hasil dari perancangan selanjutnya menjadi referensi produk serupa. Apabila tidak berhasil, maka perancangan harus dicari hal-hal yang menjadi masalah pada perancangan tersebut.

5. Specifying Learning

Proses ini digunakan untuk menentukan apakah penelitian ini tercapai atau tidak. Specifying learning sendiri dibagi menjadi tiga tahap, yaitu pertama pengetahuan baru yang diperoleh selama penelitian, kedua apabila penelitian tidak berhasil dapat memberikan pengetahuan tambahan untuk mendiagnosis persiapan penelitian tindakan lebih lanjut, ketiga keberhasilan atau kegagalan memberikan pengetahuan penting untuk penelitian di masa depan. 


\section{PERANCANGAN DAN ANALISIS}

Pembuatan motion graphic implementasi infografis pada video basic machine operation MSP melalui tahapan sesuai dengan metode penelitian action research yaitu diagnosing dan action planning, yaitu tahapan yang dilakukan sebelum melakukan proses produksi yaitu mengindentifikasi masalah utama dengan produk serupa yaitu produk video motion graphic infografis melalui aspek spatial, temporal, live action, dan typography, lalu mencari referensi object yang selanjutnya akan diubah menjadi bentuk vector kemudian melakukan tahapan pra-produksi yaitu mencari ide cerita, konsep cerita, storyboard, tipografi, warna, dan musik. Kemudian dilanjutkan dengan action taking, evaluating, dan specifying learning.

\subsection{Metode dan Penelitian}

Penelitian ini menggunakan metode action research oleh Baskerville (1999) yang menggunakan lima fase sebagai siklus action research, yaitu diagnosing (diagnosa), action planning (perencanaan tindakan), action taking (pengambilan tindakan), evaluating (evaluasi) dan specifying learning (pembelajaran spesifik).

\subsubsection{Diagnosing}

Pada proses diagnosa, penelitian yang dilakukan adalah mengidentifikasi permasalahan yang selanjutnya disimpulkan pada produk yang akan dihasilkan. Permasalahan dimulainya dari sumber informasi yang belum efektif sebagai wadah edukasi untuk karyawan di PT. Infineon Technologies Batam. Hal ini menjadi poin utama dalam pembuatan video infografis yang dihasilkan pada penelitian ini.

Salah satu referensi produk yang akan dihasilkan adalah dokumen dengan nomor Z8R0000059300000902 dan laman resmi PT. Infineon Technologies yang berisi tentang instruksi dan deskripsi bagaimana proses MSP (mark, scan, pack). Pada proses ini terdapat instruksi yang harus diperhatikan oleh karyawan yang bekerja pada bagian proses MSP, yaitu peralatan dan material yang digunakan, persiapan, aspek keamanan, hingga instruksi sebagai sumber informasi pada proses tersebut.

\subsubsection{Action Planning}

Tahap ini dilakukan perancangan produk dengan melalui tiga proses, yaitu pra-produksi, produksi, dan pasca produksi. Proses pertama yang dilakukan adalah tahapan pra-produksi, yaitu ide, konsep, storyboard, tipografi, warna, dan musik.

\subsubsection{Action Taking}

Proses action taking dilakukan pada saat proses produksi yang akan diimplementasikan pada bab selanjutnya, proses ini juga menggunakan beberapa infrastruktur baik itu pada software, maupun pada hardware.

\subsubsection{Evaluating}

Evaluasi diawali dengan pembuatan motion graphic mengenai basic machine operation MSP dan dilanjutkan dengan analisis penerapan aspek motion graphic.

Setelah melakukan tahapan tersebut pada video lalu dilanjutkan dengan melakukan evaluasi penilaian produk guna memverifikasi keabsahan materi dalam motion graphic oleh engineer leader training dan trainer operator MSP PT. Infineon Technologies Batam, selanjutnya menganalisis aspek motion graphic untuk menguji tingkat kelayakan produk yang dilakukan oleh ahli motion graphic melalui pengujian alpha dan pengujian beta.

Terakhir, dilanjutkan dengan menganalisa hasil penilaian kepada target produk yaitu karyawan operator area produksi MSP PT. Infineon Technologies Batam guna menilai tingkat keberhasilan motion graphic dalam memberikan informasi mengenai alur proses pada MSP, peringatan mengenai Keselamatan dan Kesehatan Kerja (K3) dan penggunaan Alat Pelindung Diri (APD) yang diterapkan pada PT. Infineon Technologies Batam. Hasil evaluasi dari analisa ini selanjutnya akan menjadi penentu apakah video motion graphic layak diberikan kepada perusahaan sebagai media informasi atau sebaliknya. 


\section{HASIL DAN PEMBAHASAN}

\subsection{Action Taking (Pengambilan Tindakan)}

Tahapan action taking merupakan tahapan uraian proses produksi dari infografis pada video Basic Machine Operation MSP. Tahapan ini melalui proses implementasi dari perencanaan yang telah dibuat sebelumnya. Sama seperti tahapan pembuatan infografis pada umumnya, tahapan ini menggunakan beberapa perangkat lunak untuk mendukung pembuatan video infografis.

\subsection{Evaluating}

Evaluasi yang dilakukan adalah tahapan pengujian terhadap video motion graphic yang dirancang menjadi 2 tahapan pengujian. Namun, sebelum memasuki kedua tahapan tersebut terlebih dahulu melakukan analisa terhadap produk sesuai dengan [5].

\subsubsection{Pengujian Alpha}

Penilaian awal yang dilakukan untuk mengevaluasi produk yang dibuat sesuai aspek motion graphic, sehingga kekurangan dapat dilanjutkan dengan perbaikan. Pengujian ini dilakukan oleh ahli multimedia yaitu Bapak Gendhy Dwi Harlyan, Ibu Sandi Prasetyaningsih, dan Ibu Yeni Rokhayati yang merupakan dosen di Polibatam. Pengujian dilakukan dengan mengisi kuisioner kelayakan dari video infografis basic machine operation MSP berbasis motion graphic. Setelah kuisioner terisi, selanjutnya adalah perhitungan nilai rata-rata dan menyimpulkan dari perhitungan tersebut, berhasil atau tidaknya video infografis ditampilkan kepada target audience.

\subsubsection{Pengujian Beta}

Pengujian akhir dari evaluasi produk terhadap dan tampilan motion graphic kepada target yaitu karyawan operator area produksi MSP di PT. Infineon Technologies Batam. Produk diperhatikan sebelum dipublikasi. Pengujian ini dilakukan dengan pemberian kuisioner kepada responden secara offline dan melakukan perhitungan dengan skala likert sehingga dapat menghasilkan tanggapan responden mengenai video infografis basic machine operation MSP.

\subsection{Specifying Learning}

Pada tahapan ini produk sudah selesai dan sudah melalui semua tahapan melalui pengisian penilaian oleh ahli produk dan diimplementasikan kepada target audience yaitu karyawan operator area produksi MSP PT. Infineon Technologies Batam. Penerapan aspek ini bertujuan agar infografis MSP yang dihasilkan menjadi salah satu media informasi bagi karyawan operator di area produksi MSP PT. Infineon Technologies Batam sehingga tugas utama dari basic machine operation MSP yang berbasis motion graphic terpenuhi.

\section{KESIMPULAN}

Kesimpulan yang dihasilkan dari penelitian dan dari dasar-dasar teori yang telah disusun yaitu:

1. Motion graphic pada video basic machine operation MSP (mark, scan, pack) dapat menyampaikan informasi kepada karyawan operator area produksi MSP PT. Infineon Technologies Batam mengenai alur proses pada MSP, peringatan mengenai Keselamatan dan Kesehatan kerja dan penggunaan Alat Pelindung Diri.

2. Hasil dari analisis motion graphic pada video basic machine operation MSP PT. Infineon Technologies Batam menggunakan perhitungan skala Likert bahwa 88,83\% atau "Sangat Setuju", artinya responden menyetujui jika video basic machine operation MSP berbasis motion graphic dibuat menggunakan aspek spatial, temporal, live action, dan typography. 


\section{DAFTAR PUSTAKA}

[1] Baskerville, R. L., 1999. Investigating Information System with Action Research. Communication of the Association for Information Systems, Volume 2.

[2] Cynthia Puspitawati Somantri, J. D. R. S. M., 2016. PERANCANGAN MOTION GRAPHIC EDUKASI KESEHATAN MANFAAT MENYUSUI DAN CARA MENYAPIH BERTAHAP UNTUK IBU USIA 20-30 TAHUN DI KOTA BANDUNG. e-Proceeding of Art \& Design, Volume 3, p. 688.

[3] Krum, R., 2013. Cool Infographics: Effective communication with data visualization and design. New York: Wiley Publisher.

[4] Kurniasih, N., 2016. Infografis. Prosiding Makalah Seminar Nasional "Komunikasi, Informasi dan Perpustakaan di Era Global”, pp. 456-465.

[5] Qudratina, 2018. Implementasi dan analisis aspek motion graphic pedoman gizi seimbang, Batam: Politeknik Negeri Batam.

[6] Stringer, E. T., 2014. Action Research. 4th ed. USA: SAGE Publications, Inc ... ri 2020. 